\title{
Expression of delta-like 3 is downregulated by aberrant DNA methylation and histone modification in hepatocellular carcinoma
}

\author{
YUTAKA MIZUNO $^{1}$, KENTARO MAEMURA ${ }^{1}$, YOSHIHISA TANAKA ${ }^{1}$, AZUMI HIRATA $^{1}$, SUGIKO FUTAKI ${ }^{1}$, \\ HIROKI HAMAMOTO ${ }^{2}$, KOHEI TANIGUCHI ${ }^{2}$, MICHIHIRO HAYASHI ${ }^{2}$, KAZUHISA UCHIYAMA ${ }^{2}$, \\ MASA-AKI SHIBATA $^{1}$, YOSHINORI OTSUKI ${ }^{3}$ and YOICHI KONDO ${ }^{1}$ \\ Departments of ${ }^{1}$ Anatomy and Cell Biology, ${ }^{2}$ General and Gastroenterological Surgery and \\ ${ }^{3}$ Osaka Medical College, Takatsuki, Osaka 569-8686, Japan
}

Received October 25, 2017; Accepted February 15, 2018

DOI: $10.3892 /$ or.2018.6293

\begin{abstract}
Delta-like 3 (DLL3) is a member of the Delta/Serrate/Lag-2 family of ligands for the Notch receptor and plays a role in Notch signaling. We have previously revealed that the expression of $D L L 3$ is silenced by aberrant DNA methylation and that overexpression of DLL3 in the $\mathrm{HuH} 2$ hepatocellular carcinoma (HCC) cell line induced apoptosis. In the present study, we first confirmed the methylation of DLL3 in $\mathrm{HuH} 2$ cells and analyzed the methylation status of the DLL3 promoter region by bisulfite sequencing. Furthermore, we investigated whether other epigenetic modifications, such as histone acetylation and histone methylation, affected the expression of DLL3. Treatment with the DNA methylation inhibitor, 5-azadeoxycytidine (5-Aza-dC) slightly reactivated DLL3 mRNA expression and bisulfite sequencing revealed that $\mathrm{CpG}$ sites in the DLL3 promoter region of the $\mathrm{HuH} 2$ cells were densely-methylated. In addition, a significant increase in the expression of DLL3 was observed when the cells were treated with 5-Aza-dC in combination with the histone deacetylase inhibitor trichostatin A. However, an inhibitor of the dimethylation of histone $\mathrm{H} 3$ lysine 9 (H3K9me2) or the trimethylation of histone $\mathrm{H} 3$ lysine 27 (H3K27me3), modifications that are associated with gene silencing, had no effect on $D L L 3$ reactivation. In combination with the findings from our previous study, these results indicated that DLL3 expression was silenced in HCC cells by DNA methylation and was more readily affected by histone acetylation than histone methylation (H3K9me2 or H3K27me3).
\end{abstract}

Correspondence to: Professor Kentaro Maemura, Department of Anatomy and Cell Biology, Osaka Medical College, 2-7 Daigaku-machi, Takatsuki, Osaka 569-8686, Japan

E-mail: an2011@osaka-med.ac.jp

Key words: delta-like 3, hepatocellular carcinoma, bisulfite sequencing, DNA methylation, histone acetylation, histone methylation

\section{Introduction}

Hepatocellular carcinoma (HCC) is the fifth most common cancer among men and the second most common cause of cancer mortality in both sexes $(1,2)$. Approximately $70-90 \%$ of HCC patients have a background of chronic liver disease or liver cirrhosis. Major risk factors for liver cirrhosis are chronic infection with hepatitis $\mathrm{B}$ or $\mathrm{C}$ virus, alcoholic liver disease and non-alcoholic steatohepatitis. The precise molecular mechanisms in hepatocarcinogenesis have not been fully elucidated, however a variety of organ microenvironmental factors during chronic inflammation, such as viral proteins, cytokines and reactive oxygen or nitrogen species, affect carcinogenesis through the genetic or epigenetic activation of oncogenes and/or inactivation of tumor suppressor genes. These genetic and epigenetic alterations work synergistically, leading to a multistep developmental pathway for $\operatorname{HCC}(3,4)$.

In regard to genetic alterations, whole-genome sequencing has revealed that the genes involved in chromatin regulation, such as $A R I D 1 B, A R I D 2, M L L 3$ and $M L L$, were highly mutated in HCC, although no common somatic gene mutations were found in multicentric tumor pairs from that study (5). Whole genome sequencing of hepatitis B virus-associated HCC indicated $\beta$-catenin $(C T N N B 1)$ to be the most frequently mutated oncogene $(15.9 \%)$, with TP53 being the most frequently mutated tumor-suppressor gene (35.2\%) (6). On the contrary, the epigenetic regulation of gene expression represented a complex crosstalk of DNA methylation, histone modification, chromatin remodeling, and non-coding RNAs. Of these, DNA methylation led to stable gene silencing, primarily by the covalent modification of cytosine residues within $\mathrm{CpG}$ dinucleotides.

In cancer cells, two kinds of aberrant methylation have been observed. The first one is a genome-wide hypomethylation, which causes chromosome instability, aberrant transcription or transposable element reactivation and the other is a sitespecific hypermethylation, primarily of $\mathrm{CpG}$ islands located in or around, gene promoter regions. Although most of the cytosine residues in $\mathrm{CpG}$ islands were unmethylated $(7,8)$, the aberrant methylation of tumor-suppressor gene promoters has been implicated in the development of a wide variety of cancers (9). In HCC, gene silencing associated with aberrant 
promoter hypermethylation was found in a variety of genes, such as_CDKN2A (p16), RASSF1A (Ras-association domain containing family 1), GSTPI (glutathione S-transferase) and $C D H 1$ (E-cadherin) $(10,11)$. Yoshikawa et al as well as other researchers have also revealed, using restriction landmark genomic scanning, that the suppressor of cytokine signaling-1 (SOCS-1), SOCS-3 and apoptotic speck protein-like (ASCL) genes are aberrantly methylated (12-14). Our previous methylation analysis (15) with methylation-specific PCR revealed that Delta-like 3 (DLL3), a member of the Delta/ Serrate/Lag-2 family of ligands for the Notch receptor, was frequently methylated in HCC cell lines. In the present study, we investigated the expression of DLL3 in HCC tissues by immunohistochemistry and confirmed the methylation status of the DLL3 promoter in HCC cell lines using bisulfite sequencing. Finally, we investigated the role of histone modification in the regulation of DLL3 expression in HCC cell lines.

\section{Materials and methods}

Cell culture. The HuH2 and HuH4 HCC cell lines (generous gifts from Dr. Hirohide Yoshikawa, Sasa Hospital, Tokyo, Japan) were maintained in minimum essential medium (MEM; Sigma-Aldrich, St. Louis, MO, USA) containing 10\% fetal bovine serum (FBS; Invitrogen; Thermo Fisher Scientific, Waltham, MA, USA) at $37^{\circ} \mathrm{C}$ under a $5 \% \mathrm{CO}_{2}$ atmosphere.

Tissue samples. Non-cancerous liver tissues were obtained from HCC patients who underwent surgical resection in the Department of General and Gastroenterological Surgery, Osaka Medical College (Takatsuki, Japan). Informed written consents were obtained from all patients and the study was conducted according to the guidelines of the Ethics Committee of Osaka Medical College.

Immunohistochemical study of the DLL3 expression. Human tissue arrays containing HCC cells and corresponding adjacent non-cancerous liver tissues (CSA4: Human, liver cancer-metastasis-normal; SuperBioChips, Seoul, Korea) were immunostained with anti-DLL3 antibody. Briefly, tissue array slides were deparaffinized in xylene and hydrated using an ethanol series. Endogenous peroxidase was blocked by incubating slides with $5 \mathrm{mM}$ periodic acid. Cell permeabilization was carried out by incubation with $0.5 \%$ Triton X-100 in phosphate-buffered saline (PBS) for $5 \mathrm{~min}$ at room temperature. After blocking non-specific binding with $10 \%$ bovine serum albumin in PBS, the slides were incubated with rabbit anti-human DLL3 polyclonal antibody (ARP47292_P050; Aviva Systems Biology, San Diego, CA, USA), diluted 1:1,000, at $4^{\circ} \mathrm{C}$ overnight. After washing with PBS, signals were detected using the Dako EnVision ${ }^{\text {TM }}$ Dual Link System-HRP kit (Agilent Technologies, Inc., Santa Clara, CA, USA), according to the manufacturer's protocol. After counterstaining with hematoxylin, the slides were imaged by microscopy (Eclipse E600; Nikon, Tokyo, Japan) and photographed with a CCD camera (VB-7010; Keyence, Osaka, Japan). The staining intensity of the DLL3 antibody was evaluated by three researchers (YM, KM and $\mathrm{AH})$ at separate times, and graded as either: (-), Negative; (+), weak; $(++)$, moderate; or (+++), strong.
Table I. Primer sequences for bisulfite sequencing.

\begin{tabular}{ll}
\hline F1 & 5'-TTATTATTTTGTATAGTTTTTA-3' \\
F2 & 5'-GTATAGAGTATAAAGTTATAGG-3' \\
F3 & 5'-GGTAGTTTTGGTTTATATTA-3' \\
F4 & 5'-GTATAATTTTATATATAGGT-3' \\
F5 & 5'-TTAGATATAAGGTTTGGAAGTTAG-3' \\
R1 & 5'-TAATATAAACCAAAACTACC-3' \\
R2 & 5'-ACCTATATATAAAATTATAC-3' \\
R3 & 5'-CTAACTTCCAAACCTTATATCTAA-3' \\
R4 & 5'-AAAAACCATAACCTTCTAAT-3'
\end{tabular}

The target region of the DLL3 promoter containing 26 CpGs was divided into three parts, with each part amplified by PCR using the abovementioned primers. F, forward; R, reverse; DLL3, delta-like 3.

F1 $\rightarrow$
tTaTTaTTtt gTaTagTTt taTTaTaTTC gTaTagagTa TaaagtTaTa ggtttataCg TTtataTagg atTtTTTata aaTaTaTe Co Tagagaag TagTTaTaTa gTTaTaTaat TtTaaa Cgt TaTaTaatTa CgaagtCgtg taTaTttTta gtgtTTTaTt Cgggtgt C tgTagaatTa gaattgttta TaaTTtTata aatgtgtTaa tTaTaTaTaa TtTTag\& $\mathrm{Cg}_{\mathrm{g}} \mathrm{t}$ atgTtgag $\mathrm{C}$ GTagtTTT agtggaTtT aTaatgaTaa agtTatgtgT aTTTt C.ggt agTtTtggtt TataTTaTaT aTaTaaaatT ttaaaatTat gtaTaaTTtT aTaTaTaggT ttagTTTTT aaTTTTaTTT TaTTTtagTT aTaTaaaag CgCggatT aTTTC

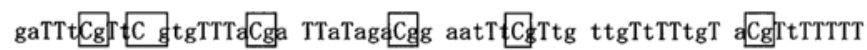

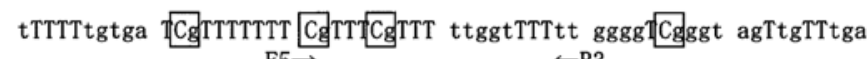

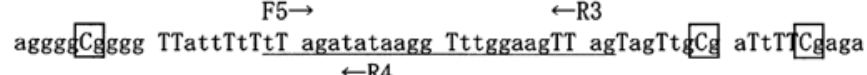
TTTTTTTaTT agaaggTTat ggtTtTTTTa CggatgtTCg ggTtTTtTtT TTagaTtgtg

Figure 1. Tentative nucleotide sequences after bisulfite treatment. Tentative nucleotide sequences of the target genomic DNA (nucleotides 103181-113850) after bisulfite treatment are displayed. Twenty-six CpG sites are enclosed with a square and the location and sequences of the forward $(F)$ and reverse (R) primers are indicated. For the first part of the target region, the primers F1/R1 (first PCR) and F2/R1 (second PCR) were used. For the middle region, F3/R4 (first PCR) and F4/R2 (second PCR) were used. For the last region, F3/R4 (first PCR) and F5/R3 (second PCR) were used. T, thymine converted from cytosine by bisulfite treatment of DNA; underlined letters indicate translation initiation site. The primer sequences are listed in Table I.

Bisulfite sequencing of $C p G$ islands in the DLL3 promoter. Genomic DNA was purified from the $\mathrm{HuH} 2$ and $\mathrm{HuH} 4$ cell lines and primary liver tissues were surgically resected, using the QIAamp DNA Mini kit (Qiagen Inc., Valencia, CA, USA). Subsequently, genomic DNA from each sample $(1 \mu \mathrm{g})$ was subjected to bisulfite treatment using the EpiTect Bisulfite kit (Qiagen), according to the manufacturer's protocol. The target region of the $D L L 3$ promoter, containing $26 \mathrm{CpG}$ sites (nucleotides 103181-113850 in AC011500), was divided into three parts, with each part amplified twice by PCR using Platinum Taq DNA polymerase (Life Technologies; Thermo Fisher Scientific, Inc.) and specific primers (Fig. 1; Table I). PCR products were cloned into pT7-Blue plasmid and 24 transformants were picked randomly. Colony PCR was carried out using M13R and U19 primers. Eight insert-positive 

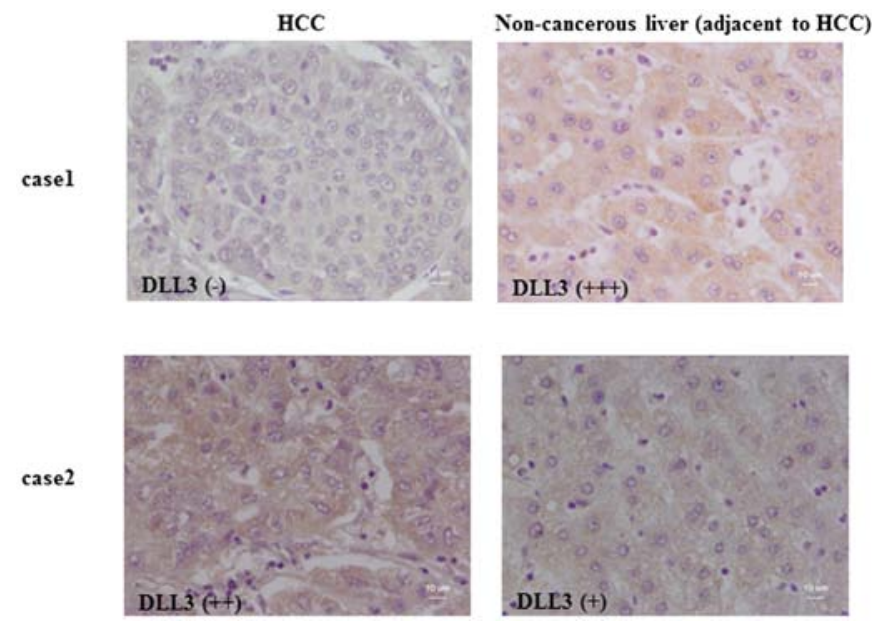

Figure 2. Immunohistochemical detection of DLL3. Positive signals were detected in the cytoplasm of hepatocytes. Upper panel: Positive signals were detected in carcinoma cells (right), whereas no signals were detected in adjacent non-cancerous hepatocytes (left). Lower panel: Moderate to strong signals were detected in the cytoplasm of both non-cancerous (left) and cancerous (right) hepatocytes. Two representative cases are displayed. HCC, hepatocellular carcinoma; DLL3, delta-like 3.

clones were subsequently amplified in $1 \mathrm{ml}$ of growth media and plasmid DNA was purified for sequencing.

Treatment with demethylating agent and histone methyltransferase inhibitors. $\mathrm{HuH} 2$ cells were incubated in media containing either 1,3 or $10 \mu \mathrm{M}$ of the demethylating agent 5-azadeoxycitidine (5-Aza-dC; Sigma-Aldrich) for $72 \mathrm{~h}$. The culture media was exchanged to a new media containing 5-Aza-dC on day 3. For the inhibition of histone deacetylation, 1 or $3 \mu \mathrm{M}$ of trichostatin A (TSA) (Sigma-Aldrich) was added to the medium on day 3 . For the inhibition of H3K9me2 dimethylation, the selective G9a and G9a-like protein histone lysine methyltransferase inhibitor BIX 01294 (Enzo Life Sciences, Inc., Farmingdale, NY, USA) was used (16). To block the trimethylation of lysine 27 on histone H3 and of lysine 20 on histone $\mathrm{H} 4$, the lysine methyltransferase EZH2 inhibitor 3-deazaneplanocin A hydrochloride (DZNep; R\&D Systems, Minneapolis, MN, USA) was used (17). DZNep (30 or $50 \mu \mathrm{M}$ final concentration) or BIX $01294(1,10$ or $30 \mu \mathrm{M}$ final concentration) was added to the culture media, either alone or together with 5-Aza-dC and TSA, on day 3. On day 4, total RNA was purified using the NucleoSpin RNA kit (Machery-Nagel $\mathrm{GmbH}$, Düren, Germany) according to the manufacturer's instructions and subjected to real-time PCR.

Real-time PCR. Real-time PCR was carried out with the StepOne Plus ${ }^{\mathrm{TM}}$ Real-Time PCR system (Applied Biosystems; Thermo Fisher Scientific) using the PrimeScript One Step RT-PCR kit (Takara Bio, Inc., Otsu, Japan), according to the manufacturer's instructions. The final $20 \mu \mathrm{l}$ reaction mixture consisted of: $10 \mu \mathrm{l}$ of $2 \mathrm{X}$ One Step RT-PCR buffer, $0.4 \mu \mathrm{l}$ of Takara Ex Taq HS (5 U/ $\mu 1), 0.4 \mu 1$ of PrimeScript RT enzyme Mix II, $1 \mu \mathrm{l}$ of the $20 \mathrm{X}$ primer-probe set, $0.4 \mu \mathrm{l}$ of ROX Reference Dye, $2 \mu \mathrm{l}$ of total RNA (100 ng/ml), and $5.8 \mu \mathrm{l}$ of RNase Free $\mathrm{dH}_{2} \mathrm{O}$. Pre-made primer and probe sets for DLL3 (Hs01085096-m1) and GAPDH (Hs032929097) as an internal standard, were purchased from Applied Biosystems
Table II. Summary of immunohistochemistry results.

\begin{tabular}{lcccc} 
Immunoreactivity & Strong (+++) & Moderate (++) & Weak (+) & None (-) \\
\hline $\begin{array}{l}\text { Non-cancerous } \\
\text { liver }\end{array}$ & 5 & 4 & 0 & 0 \\
HCC & 0 & 9 & 9 & 18 \\
\hline
\end{tabular}

The expression of DLL3 was investigated with a tissue array containing 36 HCC tissues and nine corresponding non-cancerous liver tissues. The staining intensity of DLL3 in the cytoplasm was classified as strong $(+++)$, moderate $(++)$, weak $(+)$ or none (-). HCC, hepatocellular carcinoma; DLL3, delta-like 3.

(Foster City, CA, USA). The reaction was carried out at $42^{\circ} \mathrm{C}$ for $5 \mathrm{~min}$, then at $95^{\circ} \mathrm{C}$ for $10 \mathrm{sec}$, followed by 40 cycles at $95^{\circ} \mathrm{C}$ for $5 \mathrm{sec}$ and $60^{\circ} \mathrm{C}$ for $30 \mathrm{sec}$. Relative quantification of the DLL3 expression was analyzed using the $\Delta \Delta \mathrm{Cq}$ method and the StepOne Software v2.3 (Applied Biosystems) (16).

Western blot analysis. Expression of DLL3 in $\mathrm{HuH} 2$ and $\mathrm{HuH} 4$ cells was analyzed by western blotting. For the DLL3 reactivation assay, $\mathrm{HuH} 2$ cells were cultured in media containing $1 \mu \mathrm{M}$ of 5-Aza-dC for $72 \mathrm{~h}$, replaced once on day 3 and TSA was added to the media on day 3 to give a final concentration of $1 \mu \mathrm{M}$. On day 4 , the cells were lysed in lysis buffer containing $20 \mathrm{mM}$ Tris- $\mathrm{HCl} \mathrm{pH} 8.0,150 \mathrm{mM} \mathrm{NaCl}, 1 \%$ NP-40, $0.5 \%$ deoxycholic acid, $0.1 \%$ sodium dodecyl sulfate and protease inhibitor cocktail (Roche Diagnostics $\mathrm{GmbH}$, Mannheim, Germany). The supernatant was then subjected to sodium dodecyl sulfate-polyacrylamide gel electrophoresis (SDS-PAGE) and electroblotted onto a polyvinylidene difluoride membrane (EMD Millipore, Billerica, MA, USA). The blot was blocked with 5\% skim milk in TBS for $1 \mathrm{~h}$ at room temperature and incubated with 1:100-diluted anti-DLL3 antibody (cat. no. ab103102; Abcam, Cambridge, MA, USA) overnight at $4^{\circ} \mathrm{C}$. After several washes, the blot was incubated with 1:1,000-diluted HRP-conjugated anti-rabbit IgG (cat. no. 7074; Cell Signaling Technology, Beverly, MA, USA) for $1 \mathrm{~h}$ at room temperature. Immunoreactive bands were detected with the Fusion FX chemiluminescence imaging system (Vilber Lourmat, Marne La Vallée, France), using Western Lightning ECL Pro (PerkinElmer, Waltham, MA, USA).

Statistical analysis. In all statistical analyses, normality of the data was assessed using the Shapiro-Wilk test. Differences between $\mathrm{HuH} 2$ and $\mathrm{HuH} 4$ cell lines with respect to DLL3 mRNA expression were tested by Wilcoxon test. For the comparison of data among more than three groups, the Tukey-Kramer Honest Significant Difference test was applied when the data were normally distributed. Instead, when the data were not normally distributed, Dunn's non-parametric test was performed.

\section{Results}

DLL3 expression in HCC cells. The expression of DLL3 in primary $\mathrm{HCC}$ samples and adjacent liver tissue was investigated by immunohistochemistry of tissue arrays. The results from two representative cases are displayed in Fig. 2. In case 1 , strong immunoreactivity for DLL3 was detected 
A

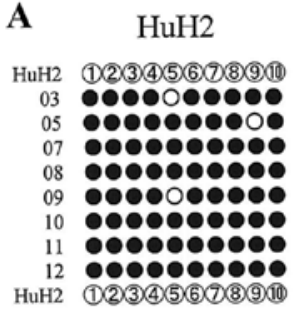

$\mathrm{HuH} 4$

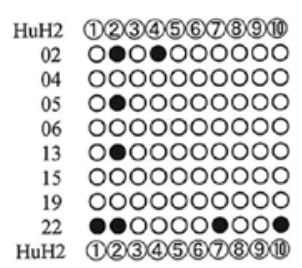

$\mathrm{HuH} 2$ (11)(12)(13)(14)(15)(16)(17)(18)(19)(212)(22)24)

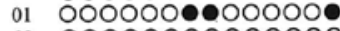

02 00000000000000

04 00000000000000

07 00000000000000

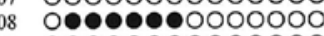

09 0000000000000

- 0000000000000

1100000000000000

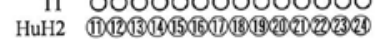
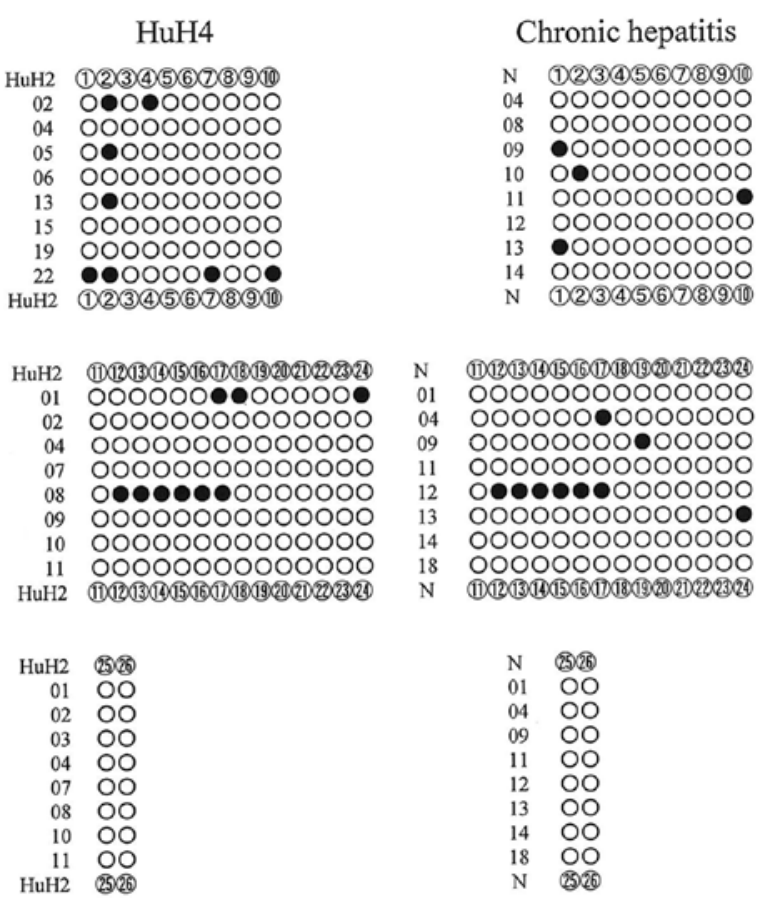

B

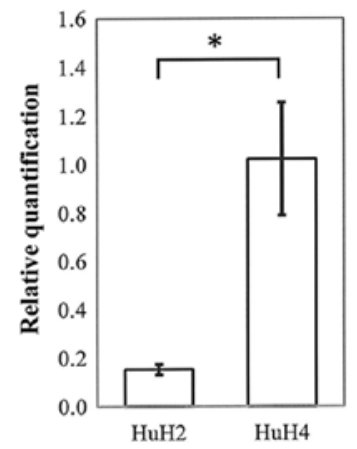

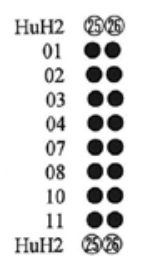

Figure 3. Methylation of DLL3 promoter and reactivation assay. (A) Bisulfite sequencing of the DLL3 promoter region. The methylation status of $26 \mathrm{CpG}$ sites in the $D L L 3$ promoter were investigated using genomic DNA from $\mathrm{HuH} 2, \mathrm{HuH} 4$ and chronic hepatitis liver specimens. Eight individual clones were randomly picked for sequencing. Filled and open circles represent methylated and unmethylated sites, respectively. (B) Real-time PCR analysis. Total RNA samples from $\mathrm{HuH} 2$ and $\mathrm{HuH} 4$ cells were analyzed by PCR using specific DLL3 primer/probe sets. Representative data from three independent experiments are displayed; data represent mean $\pm \mathrm{SD}\left(\mathrm{n}=5 ;{ }^{*} \mathrm{P}<0.05\right)$.

Table III. Summary of cell viability.

\begin{tabular}{|c|c|}
\hline Treatment & Viability $(\%)$ \\
\hline No treatment & 100 \\
\hline $1 \mu \mathrm{M} 5$-Aza-dC & 75 \\
\hline $3 \mu \mathrm{M} 5-\mathrm{Aza}-\mathrm{dC}$ & 25 \\
\hline $10 \mu \mathrm{M} 5-\mathrm{Aza}-\mathrm{dC}$ & 10 \\
\hline $1 \mu \mathrm{M}$ TSA & 95 \\
\hline $3 \mu \mathrm{M}$ TSA & 95 \\
\hline $1 \mu \mathrm{M} 5$-Aza-dC $+1 \mu \mathrm{M}$ TSA & 55 \\
\hline $1 \mu \mathrm{M} 5-\mathrm{Aza}-\mathrm{dC}+3 \mu \mathrm{M}$ TSA & 75 \\
\hline $30 \mu \mathrm{M}$ DZNep & 100 \\
\hline $50 \mu \mathrm{M}$ DZNep & 100 \\
\hline $1 \mu \mathrm{M} 5$-Aza-dC $+1 \mu \mathrm{M}$ TSA $+30 \mu \mathrm{M}$ DZNep & 25 \\
\hline $1 \mu \mathrm{M} 5-A z a-d C+1 \mu \mathrm{M}$ TSA $+50 \mu \mathrm{M}$ DZNep & 30 \\
\hline $1 \mu \mathrm{M}$ BIX 01294 & 100 \\
\hline $10 \mu \mathrm{M}$ BIX 01294 & 100 \\
\hline $1 \mu \mathrm{M} 5-\mathrm{Aza}-\mathrm{dC}+1 \mu \mathrm{M}$ TSA $+1 \mu \mathrm{M}$ BIX 01294 & 40 \\
\hline $1 \mu \mathrm{M} 5$-Aza-dC $+1 \mu \mathrm{M}$ TSA $+10 \mu \mathrm{M}$ BIX 01294 & 30 \\
\hline
\end{tabular}

$\mathrm{HuH} 2$ cells were treated with the reagents indicated and then cell viability was evaluated by counting cells attached to the culture plates using phase-contrast microscopy on day 4 of the treatment. Representative data are shown. 5-Aza-dC, 5-azadeoxycytidine; TSA, trichostatin A; DZNep, 3-deazaneplanocin A hydrochloride.

in the cytoplasm of non-cancerous hepatocytes, whereas no signal was detected in adjacent cancer cells. In case 2, DLL3 was expressed both in non-cancerous hepatocytes and the adjacent HCC cells. A summary of the immunohistochem- istry results from all cases is provided in Table II. Moderate to strong immunoreactivity against DLL3 was detected in non-cancerous hepatocytes in all cases (9/9), whereas for half of the HCC cases (18/36), no immunoreactivity could be detected. No DLL3 immunoreactivity was detected in two cases of cholangiocellular carcinoma cells (data not shown).

Methylation analysis of the DLL3 promoter and expression of DLL3 in HCC cells. The methylation status of CpG sites presented in the DLL3 promoter region was investigated by bisulfite sequencing. In Fig. 1 tentative nucleotide sequences of the target DLL3 promoter region after bisulfite treatment are displayed. As displayed in Fig. 3A, CpG sites in the DLL3 promoter region were densely methylated (closed circles) in $\mathrm{HuH} 2$ cells in all randomly selected clones, whereas the $\mathrm{CpG}$ sites were rarely methylated in clones derived from $\mathrm{HuH} 4$ cells or genomic DNA from the liver tissues of chronic hepatitis patients (Fig. 3A). Real-time RT-PCR analysis revealed that DLL3 mRNA expression in $\mathrm{HuH} 4$ cells was significantly $(\mathrm{P}=0.005)$ higher than in $\mathrm{HuH} 2$ cells (Fig. 3B).

$D L L 3$ reactivation using the demethylating agent 5-Aza- $d C$. When the deoxycytidine analogue $5-A z a-d C$ is taken up by the cells, it is incorporated into DNA and inhibits methyltransferase activity, resulting in DNA demethylation. Although demethylation by 5 -Aza-dC induces reactivation of silent genes, it can be toxic to cultured cells (17). Thus, we first investigated the survival of HCC cells after administration of 5-Aza-dC to determine the optimal dose for subsequent DLL3 reactivation assays. As summarized in Table III, 5-Aza-dC was cytotoxic to HCC cells in a dose-dependent manner. 


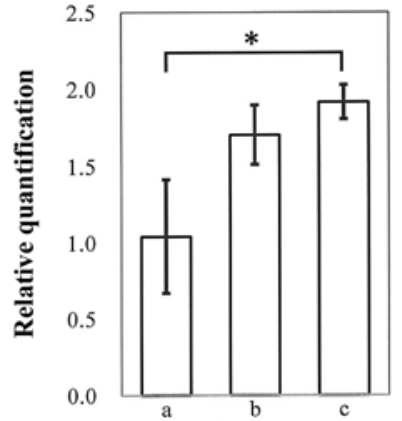

Figure 4. $D L L 3$ mRNA expression. $D L L 3$-methylated $\mathrm{HuH} 2$ cells were treated either without 5-Aza-dC (a), or with $1 \mu \mathrm{M}$ (b) or $3 \mu \mathrm{M}$ (c) of 5-Aza-dC and $D L L 3$ mRNA expression was analyzed by real-time PCR. The evaluation was performed with the $\triangle \Delta \mathrm{CT}$ method, using GAPDH as an internal control. Representative results, showing the relative mRNA expression in $\mathrm{HuH} 2$ cells under each condition vs. untreated samples, are displayed; data represent the mean $\pm \mathrm{SD}\left(\mathrm{n}=5 ;{ }^{*} \mathrm{P}<0.05\right)$

HuH2 cell confluency was $\sim 25 \%$ or less after 4 days of treatment with either 3 or $10 \mu \mathrm{M} 5$-Aza-dC, whereas it was $75 \%$ when $\mathrm{HuH} 2$ cells were treated with $1 \mu \mathrm{M} 5$-Aza-dC. Thus, we evaluated the effect of 5-Aza-dC on DLL3 reactivation at the concentration of 1 or $3 \mu \mathrm{M}$. We found that when the $\mathrm{HuH} 2$ cells were treated with 1 or $3 \mu \mathrm{M} 5$-Aza-dC for 4 days, the expression of DLL3 mRNA was reactivated up to two-fold. Treatment with $3 \mu \mathrm{M} 5$-Aza-dC induced a significant $(\mathrm{p}=0.03)$ increase in DLL3 mRNA expression, although it also had a cytotoxic effect (Fig. 4).

DLL3 reactivation using inhibitors of histone modification. The effects of histone deacetylation, histone $\mathrm{H} 3$ lysine 9 dimethylation and lysine 27 trimethylation on DLL3 expression were investigated using specific inhibitors. Treatment with 1 or $3 \mu \mathrm{M}$ of the histone deacetylase (HDAC) inhibitor TSA alone, did not cause cellular toxicity in $\mathrm{HuH} 2$ cells (Table III). DLL3 mRNA expression was significantly $(\mathrm{P}=0.0005)$ upregulated in the presence of $1 \mu \mathrm{M}$ of TSA, whereas $3 \mu \mathrm{M}$ TSA had only a slight effect. When cells were treated with $1 \mu \mathrm{M}$ of TSA together with 1 or $3 \mu \mathrm{M}$ (data not shown) of 5-Aza-dC, cell confluency was around 50-70\%, indicating that cell damage was less serious. Notably, $1 \mu \mathrm{M}$ of TSA in combination with 5-Aza-dC revealed a marked synergistic effect on DLL3 mRNA expression $(\mathrm{P}<0.0001$, compared to no treatment controls), without inducing serious cytotoxicity (Fig. 5A).

The H3 lysine 9 methyltransferase inhibitor BIX 01294 at 1 or $10 \mu \mathrm{M}$ did not induce cell damage in HuH2 cells (Table III), whereas the higher dose $(30 \mu \mathrm{M})$ was cytotoxic, with cell confluency being around $5 \%$ on day 4 (data not shown). Treatment with BIX 01294 alone did not affect DLL3 mRNA expression however and no synergistic effect was observed when the cells were treated with BIX $01294(1$ or $3 \mu \mathrm{M})$ together with both 5-Aza-dC and TSA (Fig. 5B). Similarly, the inhibitor of trimethylation of lysine 27 on histone $\mathrm{H} 3$ and lysine 20 on histone $\mathrm{H} 4$ (DZNep) did not induce DLL3 reactivation in $\mathrm{HCC}$ cells. When DZNep (30 or $50 \mu \mathrm{M}$ ) was administered together with both 5-Aza-dC $(1 \mu \mathrm{M})$ and TSA $(1 \mu \mathrm{M}), D L L 3$ expression was not reactivated, but rather suppressed, without affecting cytotoxicity (Fig. 5C; Table III).
A

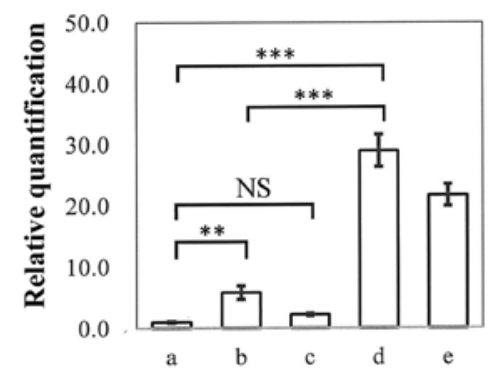

B

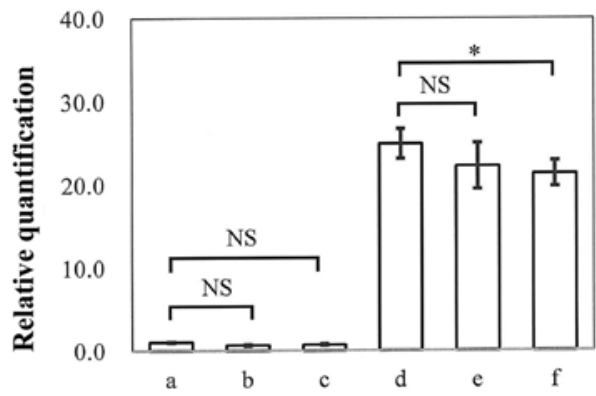

C

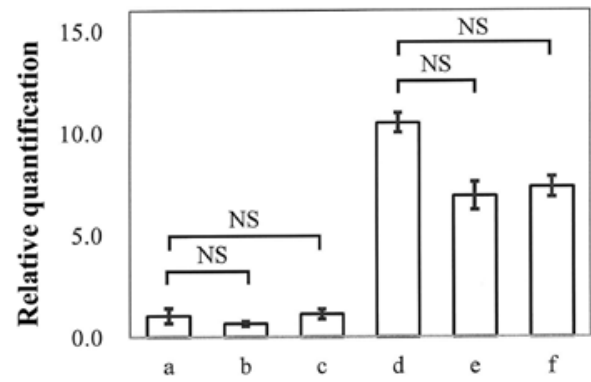

Figure 5. DLL3 mRNA expression. Real-time PCR was carried out and evaluated using the $\triangle \triangle \mathrm{CT}$ method, with GAPDH as an internal control. RNA was purified from $\mathrm{HuH} 2$ cells that had been treated as follows: (A) Without TSA (a) or with $1 \mu \mathrm{M}$ TSA (b), $3 \mu \mathrm{M}$ TSA (c), $1 \mu \mathrm{M} 5$-Aza-dC $+1 \mu \mathrm{M}$ TSA (d), $1 \mu \mathrm{M} 5$-Aza-dC $+3 \mu \mathrm{M}$ TSA (e). (B) Without treatment (a), or with $1 \mu \mathrm{M}$ BIX 01274 (b), $10 \mu \mathrm{M}$ BIX 01274 (c), $1 \mu \mathrm{M} 5$-Aza-dC $+1 \mu \mathrm{M}$ TSA (d), $1 \mu \mathrm{M} 5-A z a-d C+1 \mu \mathrm{M}$ TSA $+1 \mu \mathrm{M}$ BIX 01274 (e), $1 \mu \mathrm{M}$ 5-Aza-dC $+1 \mu \mathrm{M}$ TSA $+10 \mu \mathrm{M}$ BIX 01274 (f). (C) Without treatment (a), or with $30 \mu \mathrm{M}$ DZNep (b), $50 \mu \mathrm{M}$ DZNep (c), $1 \mu \mathrm{M}$ 5-Aza-dC $+1 \mu \mathrm{M}$ TSA (d), $1 \mu \mathrm{M} 5$-Aza-dC $+1 \mu \mathrm{M}$ TSA $+30 \mu \mathrm{M}$ DZNep (e), $1 \mu \mathrm{M} 5$-Aza-dC $+1 \mu \mathrm{M}$ TSA $+50 \mu \mathrm{M}$ DZNep (f). Representative data, indicating relative mRNA expression vs. untreated samples are shown; data represent the means \pm SD $\left(\mathrm{n}=5 ;{ }^{* * * *} \mathrm{P}<0.001 ;{ }^{*} \mathrm{P}<0.05 ; \mathrm{NS}\right.$, not significant).

\section{Discussion}

In the present study it was demonstrated that downregulation of the expression of DLL3 occured in hepatocarcinogenesis through epigenetic mechanisms, predominately DNA methylation and histone acetylation. In mammals, DNA methylation primarily occurs by covalent addition of a methyl-group at the $\mathrm{C} 5$ position of cytosine residues in $\mathrm{CpG}$ dinucleotides. Dinucleotide clusters of $\mathrm{CpGs}$ or $\mathrm{CpG}$ islands, are typically found in, or near, the promoter regions of genes. Although most $\mathrm{CpGs}$ in genomic DNA are methylated, $\mathrm{CpG}$ islands in gene promoter regions remain unmethylated, allowing transcription to occur (18). In the present study, we detected densely-methylated CpG sites in the DLL3 promoter region of $\mathrm{HuH} 2 \mathrm{HCC}$ cells using bisulfite sequencing and demonstrated that DLL3 expression could be reactivated by treatment with the demethylating agent 5-Aza-dC. These results supported the data of our previous study (15), generated using methyla- 
tion-specific PCR, that DLL3 expression was silenced by DNA methylation in several HCC cell lines. Methylated DNA itself inhibited transcriptional activation by blocking the access of transcription factors to their binding sites (19). In addition, methylated DNA may be specifically recognized by a set of methyl-CpG binding domain proteins, leading to gene supression by the recruitment of additional proteins, such as HDACs, to these loci (7).

DNA is packaged in the form of chromatin, with nucleosomes (a basic structural unit of chromatin) being comprised of histone octamers (each consists of two copies of each of the four core histone proteins $\mathrm{H} 2 \mathrm{~A}, \mathrm{H} 2 \mathrm{~B}, \mathrm{H} 3$ and $\mathrm{H} 4$ ) that are wrapped by a 146 bp length of DNA. The N- and C-terminal histone tails protrude from the nucleosome and provide sites on specific residues for covalent modification, such as acetylation, methylation, phosphorylation, sumoylation and ubiquitylation (20). These modifications regulate chromatin structure to provide binding sites for the recruitment of other molecules (21). Among these modifications, histone acetylation has been the most extensively studied and it has been demonstrated that histone acetylation/deacetylation is involved in transcriptional activation - serving as a switch between supressive and permissive chromatin states $(22,23)$. Histone acetylation is enriched in transcriptionally-active regions and is typically found on histone $\mathrm{H} 3$ and $\mathrm{H} 4$ tails (21). Histone acetylation and deacetylation is catalyzed by histone acetyl-transferases (HATs) and HDACs, respectively and acetylation status is thus regulated by a balance in the activities of these enzymes. Acetylation of the histone $\mathrm{N}$-terminus removes positive charge and the overall charge of the histone tail thus becomes neutral, reducing the affinity between DNA and histone and allowing transcription factors to access promotor regions (23).

Acetylation of specific lysine residues on particular histones is involved in the promotion of gene transcription. For example, acetylation of lysine 9 on histone H3 (H3K9ac), mainly catalyzed by GCN5/PCAF acetyltransferase and/or Tip 60 and Lysine 14 (H3K14ac), catalyzed by GCN5/PCAF, p300/CBP and/or Myst3, can be observed (24). Conversly, deacetylation of histones by HDACs has the opposite effect and negatively regulates transcriptional activity. Thus far, 18 HDAC enzymes (HDACs 1-11, and sirtuin 1-7) have been identified in mammals and can be classified into four main $\mathrm{Zn}^{2+}$-dependent groups (classes I, IIa, IIb and IV), as well as a group of nicotinamide dehydrogenase-dependent class III HDACs $(25,26)$. Although histones are the most studied substrate for HDACs, there are a wide variety of non-histone targets, including DNA-binding transcription factors (p53, c-Myc and NF- $\kappa \mathrm{B}$ ), steroid receptors (androgen receptor and estrogen receptor $\alpha$ ), chaperone proteins (HSP90), structural proteins ( $\alpha$-tubulin) and signaling mediators (STAT3, Smad7 and $\beta$-catenin) (27). The expression levels of HDACs vary by cell type and since they play pivotal roles in cell proliferation and cell death, these enzymes have become important therapeutic targets for treating various types of cancer $(28,29)$. Thus far, a range of HDAC inhibitors have been identified, which are either natural products or synthetic compounds and which have differing target-specificities and activities. Although the precise mechanism is unclear, some HDAC inhibitors are effective in treating malignant diseases. Vorinostat (suberoylanilide hydroxamic acid or SAHA) binds to the catalytic domain of HDACs and has been demonstrated to inhibit the activity of HDAC1, 2, 3 and 6 (27,30). Vorinostat induces apoptosis and has anti-proliferative effects against cancer cell lines and was approved by the FDA in 2006 to be used in the management of cutaneous T-cell lymphoma. TSA, conversly, an antifungal antibiotic derived from Streptomyces, is a potent reversible inhibitor of class I, II and IV HDACs (27). TSA inhibits both G1- and G2-phases of the mammalian cell cycle and has been tested as a potential anticancer agent $(31,32)$. In the present study, as displayed in Figs. 3 and 4, treatment with 5-Aza-dC alone exerted only a slight effect on DLL3 reactivation, whereas TSA together with 5-Aza-dC exhibited a much more potent effect. We further investigated the effect of siRNAs for HDAC1, 2 and 3 on DLL3 reactivation, but neither individual nor synergistic effects were observed (data not shown). These results indicated that class II and/or class III HDACs may play an important role in DLL3 activation.

Histone methylation, catalyzed by histone methyltransferases, is another major chromatin modification and causes transcriptional supression or activation depending on which amino acids are methylated and the degree of methylation. Lysine is able to be mono-, di- or trimethylated, with a methyl group replacing each hydrogen atom of its $\mathrm{NH}_{3}{ }^{+}$group. With a free $\mathrm{NH}_{2}$ and $\mathrm{NH}_{3}{ }^{+}$group, arginine is able to be mono- or dimethylated (21). Active genes are typically associated with di- or tri-methylation of H3 lysine 4 (H3K4me2/3) and H3K79me3 and supressed genes typically carry H3K9me2 and H3K 27 me $3(21,33)$. Therefore, we investigated the involvement of H3K9me2 and H3K27me3 in silencing of the DLL3 expression. As displayed in Fig. 4, neither DZNep, an inhibitor of histone methyltransferase EZH2-mediated trimethylation of H3K27, nor BIX 01294, an inhibitor of G9a histone methyltransferase with a strong activity towards $\mathrm{H} 3 \mathrm{~K} 9$, had individual or synergistic effects on DLL3 expression.

It has been reported that DLL3 is detected in the Golgi apparatus and rarely on the cell surface (34). Thus, DLL3 does not bind cell surface Notch receptors to activate Notch signaling, however, DLL3 suppressed Notch signaling in a cell-autonomous manner (34). Notch signaling plays an important role in liver development by regulating a fate choice between hepatocytes and biliary epithelial cells and in the regulation of hepatoblast differentiation (35-37). In addition, it has been reported that Notch signaling is activated in human HCC and hepatocyte-specific expression of intracellular domain of Notch promotes formation of liver tumors in mice (38). Thus, silencing of DLL3 in HCC hampers inactivation of Notch signaling, which may contribute to hepatocarcinogenesis.

Although natural inducers of epigenetic aberrations have not yet been fully elucidated, it has been reported that age (39), chronic inflammation (40-42) and viral (43) or bacterial infections (44) may induce such changes. As detailed clinical information in regard to such factors such as the presence of chronic inflammation or viral infections was not available for the patient material included in the present study, further investigation using clinical specimens will be necessary to clarify the precise mechanisms that contribute to the epigenetic regulation of DLL3 expression. Our preliminary data revealed that infection of hepatitis virus affected the silencing of DLL3 
expression in HCC (unpublished data), thus the levels of DLL3 expression in HCC in the present study may have been influenced by the status of the viral infection (Fig. 1; cases 1 and 2).

In conclusion, both our previous and current results indicated that in addition to DNA methylation, acetylation of lysine residues, rather than the methylation of lysine, played a pivotal role in post-transcriptional downregulation of DLL3 expression during hepatocarcinogenesis. Regulation of $D L L 3$ expression through epigenetic mechanisms may thus be associated with the development of Notch-dependent HCC, with $D L L 3$ representing a potential molecular target for therapy.

\section{Acknowledgements}

The authors wish to thank Rintaro Oide for technical assistance and Tadashi Kanayama for writing assistance.

\section{Funding}

Not applicable.

\section{Availability of data and materials}

The datasets used and/or analyzed during the present study are available from the corresponding author on reasonable request.

\section{Authors' contributions}

MY and KM designed the experiments and interpreted the data. KM, YT and $\mathrm{HH}$ performed real-time PCR analysis and AH performed histological examinations of the HCC tissue array. SF performed statistical analysis of the obtained data. $\mathrm{KT}, \mathrm{MH}$, and $\mathrm{KU}$ operated the $\mathrm{HCC}$ patients and prepared clinical samples. MS contributed to draft the manuscript. YO and KY carefully read the manuscript and revised it critically. All authors read and approved the final manuscript.

\section{Ethics approval and consent to participate}

The present study was conducted according to the guidelines of the Ethics Committee of Osaka Medical College.

\section{Consent for publication}

Informed written consent was obtained from the patient.

\section{Competing interests}

The authors declare that they have no competing interests.

\section{References}

1. Ryerson AB, Eheman CR, Altekruse SF, Ward JW, Jemal A, Sherman RL, Henley SJ, Holtzman D, Lake A, Noone AM, et al: Annual report to the nation on the status of cancer, 1975-2012, featuring the increasing incidence of liver cancer. Cancer 122: 1312-1337, 2016.

2. de Martel C, Maucort-Boulch D, Plummer M and Franceschi S: World-wide relative contribution of hepatitis $\mathrm{B}$ and $\mathrm{C}$ viruses in hepatocellular carcinoma. Hepatology 62: 1190-1200, 2015.

3. Herath NI, Leggett BA and MacDonald GA: Review of genetic and epigenetic alterations in hepatocarcinogenesis. J Gastroenterol Hepatol 21: 15-21, 2006.
4. Kondoh N, Wakatsuki T, Hada A, Shuda M, Tanaka K, Arai M and Yamamoto M: Genetic and epigenetic events in human hepatocarcinogenesis. Int J Oncol 18: 1271-1278, 2001.

5. Fujimoto A, Totoki Y, Abe T, Boroevich KA, Hosoda F, Nguyen HH, Aoki M, Hosono N, Kubo M, Miya F, et al: Whole-genome sequencing of liver cancers identifies etiological influences on mutation patterns and recurrent mutations in chromatin regulators. Nat Genet 44: 760-764, 2012.

6. Kan Z, Zheng H, Liu X, Li S, Barber TD, Gong Z, Gao H, Hao K, Willard MD, Xu J, et al: Whole-genome sequencing identifies recurrent mutations in hepatocellular carcinoma. Genome Res 23: 1422-1433, 2013.

7. Sharma S, Kelly TK and Jones PA: Epigenetics in cancer. Carcinogenesis 31: 27-36, 2010.

8. Fatemi M, Pao MM, Jeong S, Gal-Yam EN, Egger G, Weisenberger DJ and Jones PA: Footprinting of mammalian promoters: Use of a CpG DNA methyltransferase revealing nucleosome positions at a single molecule level. Nucleic Acids Res 33: e176, 2005

9. Calvisi DF, Ladu S, Gorden A, Farina M, Lee JS, Conner EA, Schroeder I, Factor VM and Thorgeirsson SS: Mechanistic and prognostic significance of aberrant methylation in the molecular pathogenesis of human hepatocellular carcinoma. J Clin Invest 117: 2713-2722, 2007.

10. Pogribny IP and Rusyn I: Role of epigenetic aberrations in the development and progression of human hepatocellular carcinoma. Cancer Lett 342: 223-230, 2014.

11. Wahid B, Ali A, Rafique S and Idrees M: New insights into the epigenetics of hepatocellular carcinoma. Biomed Res Int 2017: $1609575,2017$.

12. Yoshikawa H, Matsubara K, Qian GS, Jackson P, Groopman JD, Manning JE, Harris CC and Herman JG: SOCS-1, a negative regulator of the JAK/STAT pathway, is silenced by methylation in human hepatocellular carcinoma and shows growth-suppression activity. Nat Genet 28: 29-35, 2001.

13. Niwa Y, Kanda H, Shikauchi Y, Saiura A, Matsubara K, Kitagawa T, Yamamoto J, Kubo T and Yoshikawa H: Methylation silencing of SOCS-3 promotes cell growth and migration by enhancing JAK/STAT and FAK signalings in human hepatocellular carcinoma. Oncogene 24: 6406-6417, 2005.

14. Kubo T, Yamamoto J, Shikauchi Y, Niwa Y, Matsubara K and Yoshikawa H: Apoptotic speck protein-like, a highly homologous protein to apoptotic speck protein in the pyrin domain, is silenced by DNA methylation and induces apoptosis in human hepatocellular carcinoma. Cancer Res 64: 5172-5177, 2004.

15. Maemura K, Yoshikawa H, Yokoyama K, Ueno T, Kurose H, Uchiyama K and Otsuki Y: Delta-like 3 is silenced by methylation and induces apoptosis in human hepatocellular carcinoma. Int J Oncol 42: 817-822, 2013.

16. Tachibana M, Sugimoto K, Fukushima T and Shinkai Y: Set domain-containing protein, G9a, is a novel lysine-preferring mammalian histone methyltransferase with hyperactivity and specific selectivity to lysines 9 and 27 of histone H3. J Biol Chem 276: 25309-25317, 2001

17. Glazer RI, Knode MC, Tseng CK, Haines DR and Marquez VE: 3-Deazaneplanocin A: A new inhibitor of S-adenosylhomocysteine synthesis and its effects in human colon carcinoma cells. Biochem Pharmacol 35: 4523-4527, 1986.

18. Livak KJ and Schmittgen TD: Analysis of relative gene expression data using real-time quantitative PCR and the 2(-Delta Delta C(T)) method. Methods 25: 402-408, 2001.

19. Jüttermann R, Li E and Jaenisch R: Toxicity of 5-aza-2'-deoxycytidine to mammalian cells is mediated primarily by covalent trapping of DNA methyltransferase rather than DNA demethylation. Proc Natl Acad Sci USA 91: 11797-11801, 1994.

20. Bird A: DNA methylation patterns and epigenetic memory. Genes Dev 16: 6-21, 2002.

21. Choy MK, Movassagh M, Goh HG, Bennett MR, Down TA and Foo RS: Genome-wide conserved consensus transcription factor binding motifs are hyper-methylated. BMC Genomics 11: 519, 2010.

22. Kouzarides T: Chromatin modifications and their function. Cell 128: 693-705, 2007.

23. Zhang T, Cooper S and Brockdorff N: The interplay of histone modifications-writers that read. EMBO Rep 16: 1467-1481, 2015.

24. Jin B, Li Y and Robertson KD: DNA methylation: Superior or subordinate in the epigenetic hierarchy? Genes Cancer 2: 607-617, 2011.

25. Eberharter A and Becker PB: Histone acetylation: A switch between repressive and permissive chromatin. Second in review series on chromatin dynamics. EMBO Rep 3: 224-229, 2002. 
26. Farria A, Li W and Dent SY: KATs in cancer: Functions and therapies. Oncogene 34: 4901-4913, 2015.

27. de Ruijter AJ, van Gennip AH, Caron HN, Kemp S and van Kuilenburg AB: Histone deacetylases (HDACs): Characterization of the classical HDAC family. Biochem J 370 : 737-749, 2003.

28. Delcuve GP, Khan DH, and Davie JR: Roles of histone deacetylases in epigenetic regulation: emerging paradigms from studies with inhibitors. Clinical Epigenetics 4: 5, 2012.

29. Xu WS, Parmigiani RB and Marks PA: Histone deacetylase inhibitors: Molecular mechanisms of action. Oncogene 26 5541-5552, 2007

30. West AC and Johnstone RW: New and emerging HDAC inhibitors for cancer treatment. J Clin Invest 124: 30-39, 2014.

31. Eckschlager T, Plch J, Stiborova $M$ and Hrabeta J: Histone deacetylase inhibitors as anticancer drugs. Int J Mol Sci 18 : E1414, 2017.

32. Richon VM: Cancer biology: Mechanism of antitumour action of vorinostat (suberoylanilide hydroxamic acid), a novel histone deacetylase inhibitor. Br J Cancer 95 (S1): S2-S6, 2006

33. Li B, Carey M and Workman JL: The role of chromatin during transcription. Cell 128: 707-719, 2007.

34. Geffers I, Serth K, Chapman G, Jaekel R, Schuster-Gossler K, Cordes R, Sparrow DB, Kremmer E, Dunwoodie SL, Klein T, et al: Divergent functions and distinct localization of the Notch ligands DLL1 and DLL3 in vivo. J Cell Biol 178: 465-476, 2007.

35. Kodama Y, Hijikata M, Kageyama R, Shimotohno K and Chiba T: The role of notch signaling in the development of intrahepatic bile ducts. Gastroenterology 127: 1775-1786, 2004.

36. Ader T, Norel R, Levoci L and Rogler LE: Transcriptional profiling implicates TGFbeta/BMP and Notch signaling pathways in ductular differentiation of fetal murine hepatoblasts. Mech Dev 123: 177-194, 2006.

37. Zong Y, Panikkar A, Xu J, Antoniou A, Raynaud P, Lemaigre F and Stanger BZ: Notch signaling controls liver development by regulating biliary differentiation. Development 136: 1727-1739, 2009.
38. Villanueva A,Alsinet C, Yanger K, Hoshida Y,Zong Y, Toffanin S, Rodriguez-Carunchio L, Solé M, Thung S, Stanger BZ, et al: Notch signaling is activated in human hepatocellular carcinoma and induces tumor formation in mice. Gastroenterology 143: 1660-1669.e7, 2012.

39. Issa JP, Ottaviano YL, Celano P, Hamilton SR, Davidson NE and Baylin SB: Methylation of the oestrogen receptor $\mathrm{CpG}$ island links ageing and neoplasia in human colon. Nat Genet 7: 536-540, 1994.

40. Hsieh CJ, Klump B, Holzmann K, Borchard F, Gregor M and Porschen R: Hypermethylation of the p16INK4a promoter in colectomy specimens of patients with long-standing and extensive ulcerative colitis. Cancer Res 58: 3942-3945, 1998.

41. Kondo Y, Kanai Y, Sakamoto M, Mizokami M, Ueda R and Hirohashi S: Genetic instability and aberrant DNA methylation in chronic hepatitis and cirrhosis - A comprehensive study of loss of heterozygosity and microsatellite instability at 39 loci and DNA hypermethylation on $8 \mathrm{CpG}$ islands in microdissected specimens from patients with hepatocellular carcinoma. Hepatology 32: 970-979, 2000.

42. Wang JS, Guo M, Montgomery EA, Thompson RE, Cosby $\mathrm{H}$, Hicks L, Wang S, Herman JG and Canto MI: DNA promoter hypermethylation of p16 and APC predicts neoplastic progression in Barrett's esophagus. Am J Gastroenterol 104: 2153-2160, 2009.

43. Chang MS, Uozaki H, Chong JM, Ushiku T, Sakuma K, Ishikawa S, Hino R, Barua RR, Iwasaki Y, Arai K, et al: CpG island methylation status in gastric carcinoma with and without infection of Epstein-Barr virus. Clin Cancer Res 12: 2995-3002, 2006.

44. Park SY, Yoo EJ, Cho NY, Kim N and Kang GH: Comparison of $\mathrm{CpG}$ island hypermethylation and repetitive DNA hypomethylation in premalignant stages of gastric cancer, stratified for Helicobacter pylori infection. J Pathol 219: 410-416, 2009. 